\title{
PENERAPAN SASARAN KESELAMATAN PASIEN DI RUANG RAWAT INAP
}

\author{
Kiki Ramadhani \\ Email : Kikiirmdhn@gmail.com
}

\section{Latar Belakang}

Keselamatan pasien (patient safety) merupakan suatu variabel dalam mengukur dan mengevaluasi kualitas pelayanan keperawatan yang berdampak terhadap pelayanan kesehatan yang diberikan. Program keselamatan pasien bertujuan untuk menurunkan angka Kejadian Tidak Diharapkan (KTD) yang sering terjadi pada pasien selama dirawat di rumah sakit sehingga sangat merugikan baik pasien sendiri maupun pihak rumah sakit. Sasaran Keselamatan Pasien (SKP) menjadi indikator standar dasar yang utama dalam penilaian Akreditasi Rumah Sakit versi 2012 (KARS, 2013). Ada enam sasaran keselamatan pasien yaitu Ketepatan identifikasi pasien; Peningkatan komunikasi yang efektif; Peningkatan keamanan obat yang perlu diwaspadai; Kepastian tepatlokasi, tepat-prosedur, tepat-pasien operasi; Pengurangan risiko infeksi terkait pelayanan kesehatan; dan Pengurangan risiko pasien jatuh (Permenkes Nomor 1691, 2011). Bentuk-bentuk kesalahan yang terjadi di rumah sakit seperti kesalahan dalam pelayanan atau pengobatan yang dikarenakan kesalahan dalam mengidentifikasi pasien dengan benar, kesalahan dalam pemberian obat dikarenakan Look-Alike Sound-Alike, kesalahan pelayanan karena komunikasi yang tidak efektif baik dari perawat-perawat atau perawatpelayanan kesehatan lain, dan terjadinya pasien jatuh yang mengakibatkan cedera pasien rawat inap, dan juga kejadian infeksi karena pedoman dalam mencuci tangan yang tidak diikuti (Kemenkes dan KARS, 2011). Berdasarkan uraian tersebut, untuk dapat membudidayakan keselamatan pasien maka langkah awal yang diperlukan bagi tenaga kesehatan adalah pengetahuan. Mengingat pentingnya bagi setiap rumah sakit untuk mengaplikasikan keselamatan pasien, dan adanya tuntutan Akreditasi, maka Secara konsep pengetahuan merupakan domain yang penting untuk terbentuknya perilaku terbuka (Sunaryo, 2004). Tujuannya adalah untuk mengidentifikasi pengetahuan tenaga kesehatan dalam Sasaran Keselamatan Pasien di rumah sakit. 


\section{Metode}

Metode yang digunakan dengan melakukan analisis data sekunder yaitu dengan mengumpulkan kajian pustaka terhadap beberapa referensi yang mendukung . Referensi-Referensi tersebut meliputi pembahasan yang bertujuan untuk mengetahui Bagaiman cara penerapan sasaran keselamatan pasien yang seharusnya di lakukan di ruang rawat inap maupun di rumah sakit.

\section{Hasil}

Patient Safety atau keselamatan pasien merupakan isu global yang sangat mempengaruhi negara-negara di seluruh dunia dalam tingkat pembangunan. Meskipun perkiraan ukuran permasalahan masih belum pasti, khususnya di negara berkembang dan negara transisi/konflik, ada kemungkinan bahwa jutaan pasien seluruh dunia menderita cacat, cedera atau meninggal setiap tahun dikarenakan pelayanan kesehatan yang tidak aman. Mengurangi kejadian yang membahayakan bagi pasien merupakan suatu masalah dalam pelayanan kesehatan bagi setiap orang, dan terdapat banyak hal yang harus dipelajari dan dibagi antara negaranegara maju dengan negara-negara berkembang dan negara dalam transisi/konflik tentang masalah keselamatan pasien (World Health Organization, 2009). WHO juga mengingatkan bahwa "keselamatan pasien tidak hanya tentang data statistik tetapi melibatkan kerusakan yang nyata pada kehidupan orang-orang". Oleh karenanya semua strategi dan program keselamatan pasien harus menjadi prioritas dalam pelayanan kesehatan. Pasien, profesional kesehatan dan pembuat kebijakan semua harus bekerja sama untuk membangun sistem kesehatan yang lebih aman. Keselamatan pasien (Patient Safety) merupakan suatu variabel untuk mengukur dan mengevaluasi kualitas pelayanan keperawatan yang berdampak terhadap pelayanan kesehatan. Sejak malpraktik menggema diseluruh belahan bumi melalui berbagai media baik cetak maupun elektronik hingga ke jurnal-jurnal ternama, dunia kesehatan mulai menaruh kepedulian yang tinggi terhadap isu keselamatan pasien (Nursalam, 2011). Keselamatan pasien (Patient Safety) merupakan sesuatu yang jauh lebih penting dari pada sekedar efisiensi pelayanan. Perilaku perawat dengan kemampuan perawat sangat berperan penting dalam pelaksanaan keselamatan pasien. Perilaku yang tidak aman, lupa, kurangnya perhatian/ motivasi, kecerobohan, tidak teliti dan kemampuan yang tidak memperdulikan dan menjaga keselamatan 
pasien berisiko untuk terjadinya kesalahan dan akan mengakibatkan cedera pada pasien, berupa Near Miss (Kejadian Nyaris Cedera/ KNC) atau Adverse Event (Kejadian Tidak Diharapkan/ KTD) selanjutnya pengurangan kesalahan dapat dicapai dengan memodifikasi perilaku (WHO, 2014 ; Lombogia et al, 2016).

\section{Pembahasan}

Menurut National Health Performance Committee (NHPC, 2001, dikutip dari Australian Institute Health and Welfare (AlHW, 2009) mendefinisikan keselamatan pasien adalah menghindari atau mengurangi hingga ketingkat yang dapat diterima dari bahaya aktual atau risiko dari pelayanan kesehatan atau lingkungan di mana pelayanan kesehatan tersebut diberikan. Fokus dari definisi ini adalah untuk mencegah hasil pelayanan kesehatan yang merugikan pasien atau yang tidak diinginkan. Institute of Medicine (2000) mendefinisikan keselamatan pasien adalah "freedom from accidental injury". Sedangkan Kelley dan Hurst (2006, dikutip dari AlHW, 2009) mendefinisikan keselamatan pasien adalah tingkat dimana menghindari, mencegah, dan memperbaiki hasil atau cedera yang merugikan dari proses pelayanan kesehatan. Bagi tenaga kesehatan khususnya dokter dan perawat diwajibkan untuk mengetahui tentang Sasaran Keselamatan Pasien. rumah sakit diwajibkan untuk meningkatkan mutu pelayanan kesehatan yang salah satunya adalah melalui sasaran keselamatan pasien. Sasaran keselamatan pasien yang dimaksud dalam akreditasi rumah sakit adalah Sasaran Keselamatan Pasien (SSP) yang terdiri dari Sasaran I adalah Ketepatan Identifikasi Pasien, Sasaran II adalah Peningkatan komunikasi yang efektif, Sasaran III adalah Peningkatan keamanan obat yang perlu diwaspadai, Sasaran IV adalah Kepastian tepat lokasi, tepat prosedur, dan tepat pasien operasi, Sasaran IV adalah Pengurangan risiko infeksi terkait pelayanan kesehatan, VI adalah Pengurangan risiko pasien jatuh (Direktoran BUN, Kemenkes, dan KARS, 2011). Keselamatan pasien perlu dibudayakan, menurut NHS (2004) bahwa budaya keselamatan pasien yang perlu dikembangkan adalah melalui pengembangan pengkajian yang meliputi senior management visibility dan komitmen keselamatan, komunikasi diantara manajer dan staf, sikap untuk melaporkan kejadian, kesalahan dan punishment. Program keselamatan pasien perlu 
dibudidayakan di rumah sakit. Berdasarkan hasil penelitian Arruum, Salbiah, Manik (2015) tentang manajemen risiko keselamatan pasien didapatkan bahwa pengaturan sistem keselamatan pasien perlu dirancang yang meliputi identifikasi, perencanaan, implementasi, dan dukungan. program keselamatan pasien tidak optimal karena adanya hambatan dalam struktur, proses dan outcome, yang diakibatkan oleh keterbatasan sumberdaya, pengelolaan manajemen, strategi-strategi yang belum efektif, sistem pelaporan insiden yang lemah, belum adanya budaya keselamatan dan fungsi kepemimpinan yang tidak efektif. Needleman dan Buerhaus (2003) menyatakan bahwa pada umumnya hasil penelitian menghasilkan tentang masalah sistem yaitu pada level system yang meliputi pada regulasi, pembayaran, sehingga harus menemukan cara untuk memonitor outcomes dan mempelajari pengalaman yang berhubungan dengan perawat. Hal tersebut mencerminkan bahwa program keselamatan pasien perlu diberdayakan di rumah sakit untuk menghindari kesalahan. Kejadian Tidak Diharapkan (KTD) yang sering terjadi pada pasien selama dirawat dapat disebabkan oleh berbagai faktor antara lain: lingkungan kerja, halhal yang berhubungan dengan kondisi pasien, alur komunikasi yang kurang tepat, penggunaan sarana kurang tepat, kebijakan dan prosedur yang tidak adekuat. Semua faktor tersebut menimbulkan terjadinya insiden keselamatan pasien yang beragam, mulai dari yang ringan dan sifatnya reversible hingga yang berat berupa kecacatan atau bahkan kematian (Iswati, 2013). Salah satu tujuan dari keselamatan pasien adalah mengurangi angka insiden keselamatan pasien (IKP). Insiden keselamatan pasien adalah setiap kejadian yang tidak disengaja dan kondisi yang mengakibatkan cedera yang dapat dicegah pada pasien. IKP terdiri dari kejadian tidak diharapkan (KTD), kejadian nyaris cedera (KNC), kejadian tidak cedera (KTC), kejadian potensial cedera (KPC) dan sentinel (Gunawan, Widodo, \& Harijanto, 2015)

Elder dan Dovey (2002), membuat sistem klasifikasi kesalahan dalam pelayanan kesehatan yang seharusnya dapat dicegah terkait dengan pelayanan primer dan kesalahan dalam proses, adalah;

1) Klasifikasi kesalahan pada pelayanan primer, meliputi; a) Terkait dengan diagnosis; salah mendiagnosis dan tertunda mendiagnosis. b) Pengobatan; salah obat, salah dosis, tertunda administrasi, tanpa administrasi, sedangkan non-obat; ketidaktepatan, terlambat, dihilangkan, komplikasi. c) Pelayanan pencegahan; terlambat, ditiadakan, komplikasi. 
2) Klasifikasi kesalahan pada proses; a) Faktor dokter; kesalahan penilaian klinis, kesalahan prosedur keterampilan, b) Faktor perawat; kesalahan komunikasi dan kesalahan prosedur keterampilan, c) Kesalahan komunikasi; dokter-pasien, dokterdokter atau sistem dan personil pelayanan kesehatan lainnya, d) Faktor administrasi; dokter, farmasi, perawat, terapi fisik, terapi pekerjaan, pengaturan kantor. e) Faktor akhir; pribadi dan masalah keluarga, dokter, perawat dan staf, peraturan perusahaan asuransi, peraturan pemerintah, pembiayaan, fasilitas dan lokasi praktek, dan sistem umum pelayanan kesehatan.

Menurut Chang, Schyve, Croteau, O'leary, dan Loeb (2005) menyatakan bahwa beberapa metode telah dikembangkan untuk menentukan dan mengklasifikasi kesalahan medis, efek samping, dan lainnya terkait dengan konsep keselamatan pasien. Namun, metode-metode tersebut cenderung menjadi sempit dan terutama hanya berfokus pada bidang tertentu pelayanan kesehatan, seperti; kesalahan obat, reaksi transfusi , perawatan primer, dan pelayanan keperawatan .

Chang, et al. (2005) mengembangkan dan menerapkan metode klasifikasi yang didasarkan pada evaluasi dari taksonomi dan pelaporan sistem dengan umpan balik dari individu yang akan menggunakan taksonomi tersebut. Pendekatan ini berusaha mengidentifikasi kesamaan dan kesenjangan dalam terminologi dan klasifikasi untuk membuat sebuah taksonomi multidimensional yang meliputi pengaturan beragam sistem pelayanan kesehatan dan pelaporan. Klasifikasi kesalahan tersebut meliputi;

1) Dampak; hasil atau efek dari kesalahan medis dan kegagalan sistem, biasanya disebut sebagai kerugian kepada pasien, 2) Jenis; hal yang tersirat atau terlihat dari proses yang salah atau gagal, 3) Domain; karakteristik pengaturan terjadi insiden dan individu yang terlibat, 4) Penyebab; faktor dan agen yang menyebabkan insiden, 5) Pencegahan dan mitigasi atau tindakan yang diusulkan dilakukan untuk mengurangi insiden dan dampak kejadian yang merugikan. Sistem Kecelakaan lebih mungkin terjadi dalam beberapa jenis sistem. Ketika kesalahan terjadi, merupakan kegagalan dalam cara merancang sistem.

Tujuan utama dari desain sistem agar kecelakaan tidak terjadi dan jikapun kesalahan terjadi dapat meminimalkan kerusakan. Dalam sistem yang kompleks, salah satu komponen sistem dapat berinteraksi dengan beberapa komponen lain, kadang- 
kadang dalam cara yang tak terduga atau tak terlihat. Meskipun semua sistem memiliki banyak bagian yang berinteraksi, masalah muncul ketika salah satu bagian sistem melayani banyak fungsi, dan jika bagian sistem ini gagal, maka semua fungsi akan gagal juga. Sistem yang kompleks ditandai oleh spesialisasi dan keterkaitan menerima informasi secara tidak langsung, dan karena spesialisasi ada sedikit kemungkinan mengganti atau pemindahan personil atau sumber daya lainny a.Semua sistem memiliki interaksi linear, namun beberapa sistem memiliki kompleksitas tambahan dan pengalaman yang lebih. Kompleksitas interaksi berkontribusi terhadap kecelakaan karena dapat membingungkan dalam pelaksanaannya. Karena kompleksitas dan rangkaian sistem yang panjang, kegagalan kecil dapat berkembang menjadi kecelakaan besar. Pelayanan kesehatan adalah sistem yang kompleks, kegiatan khas di ruang gawat darurat, ruang bedah, atau unit perawatan intensif memberikan contoh kompleksitas sistem pelayanan kesehatan. Oleh karena itu, jasa pelayanan kesehatan dengan sistem yang tidak tertata dengan baik dapat diklasifikasikan sebagai suatu industri yang rentan terhadap kecelakaan dan kesalahan. Kondisi Meskipun keputusan manajerial yang baik diperlukan untuk keamanan dan produksi yang efisien, namun itu tidak cukup. Kebutuhan untuk memiliki peralatan yang tepat, terpelihara dengan baik dan dapat diandalkan, tenaga kerja yang terampil dan berpengetahuan, jadwal kerja yang masuk akal, pekerjaan yang dirancang dengan baik; panduan yang jelas pada kinerja yang diinginkan dan tidak diinginkan, dan sebagainya. Faktor-faktor seperti ini merupakan pelopor atau prasyarat untuk proses produksi yang aman. Setiap prasyarat yang diberikan tidak jelas dapat memberi kontribusi kepada sejumlah besar tindakan yang tidak aman. Misalnya, personil yang kurang pelatihan, beban kerja tinggi, tekanan waktu berlebihan, persepsi yang tidak tepat tentang bahaya, atau kesulitan motivasi. Desain pekerjaan, pemilihan dan penggunaan peralatan, prosedur operasional, jadwal kerja, dan sebagainya, semua faktor ini dalam proses produksi dapat dirancang dalam memperbaiki kondisi untuk lebih menjamin keselamatan. Manusia Faktor manusia didefinisikan sebagai studi tentang keterkaitan antara manusia, alat-alat yang mereka gunakan, dan lingkungan dimana mereka tinggal dan bekerja. Dalam konteks ini, pendekatan faktor manusia digunakan untuk mengetahui di mana dan mengapa sistem atau proses rusak. Mempelajari kinerja manusia bisa menghasilkan penciptaan sistem yang aman dan menurunkan kondisi yang menyebabkan kesalahan. Namun, tidak semua kesalahan 
terkait dengan faktor manusia. Meskipun desain peralatan dan bahan harus mempertimbangkan cara orang dalam menggunakannya, faktor manusia tidak dapat mengatasi kerusakan peralatan atau kegagalan material. Sebagian besar mempelajari faktor manusia adalah untuk peningkatan hubungan antara sistem dengan manusia, dengan merancang sistem dan proses yang lebih baik. Termasuk; menyederhanakan dan standardisasi prosedur tindakan, meningkatkan komunikasi dan koordinasi di dalam tim, atau merancang ulang peralatan untuk meningkatkan hubungan antara manusia dengan mesin. Teknologi Menurut Carstens (2008) salah satu penyebab kesalahan pada pelayanan kesehatan adalah persoalan teknologi. Untuk mendukung pengetahuan manajemen dan pekerja pada layanan kesehatan agar mengurangi risiko kesalahan, meningkatkan keselamatan pasien, dan memperbaiki seluruh mutu pelayanan pasien diperlukan perbaikan teknologi. Carstens memperkenalkan model teknologi yang dapat mengurangi kesalahan dalam pelayanan kesehatan, dengan nama SHELL model; Software (Prosedur, Kebijakan/Peraturan, Regulasi), Hardware (Bahan, Peralatan, Fasilitas), Environment (Fisik, Ekonomi, Politik), Liveware/Worker (Pembatasan Fisik, Keterbatasan Mental, Pengetahuan/Skill, Sikap) dan Liveware/Teamwork (Komunikasi, Kepemimpinan, Norma Kelompok) Tindakan yang Tidak Tepat Masalah keselamatan pasien dari berbagai jenis terjadi selama pelayanan kesehatan berlangsung. Termasuk kesalahan transfusi dan efek samping obat, salah operasi dan luka bedah, pengendalian terkait cedera atau kematian, infeksi terkait perawatan rumah sakit, jatuh, luka bakar, ulkus decubitus, dan kesalahan identitas pasien. Leape, Lucian, Lawthers, Brennan.

Troyen (1993 dikutip dari IOM, 2000) menyebutkan ciri jenis kesalahan yang mengakibatkan cedera;

1) Diagnostik; kesalahan atau keterlambatan diagnosis, kegagalan untuk menggunakan hasil dari tes diagnostik, menggunaan tes diagnostik atau terapi yang sudah ketinggalan zaman, kegagalan untuk bertindak berdasarkan hasil pemantauan atau pengujian.

2) Pengobatan; kesalahan dalam pelaksanaan operasi, prosedur, atau uji, kesalahan dalam mengelola perawatan, kesalahan dalam dosis atau metode menggunakan obat, keterlambatan dalam pengobatan atau dalam menanggapi tes abnormal, dan 
tidak menunjukan kepedulian.

3) Pencegahan; kegagalan untuk memberikan profilaksis, pemantauan yang tidak memadai atau tindak melanjutkan pengobatan.

4) Lain-lain; kegagalan komunikasi, kegagalan peralatan, kegagalan sistem Kesalahan obat Memastikan penggunaan obat yang sesuai merupakan proses yang kompleks melibatkan beberapa organisasi dan para profesional dari berbagai disiplin ilmu, misalnya; pengetahuan obat, akses yang tepat terhadap informasi obat, pasien yang akurat, dosis yang tepat, cara yang benar, kegagalan untuk memberikan obat yang diresepkan dan serangkaian keputusan yang saling terkait selama periode waktu pengobatan. Pasien juga membuat kesalahan dalam masalah obat, khususnya pada pasien atau masyarakat yang mengalami perawatan jangka panjang, dan mengalami ketergantungan lebih besar pada terapi obat yang kompleks. Kesalahan obat sering dapat dicegah, meskipun untuk mengurangi kesalahan pada tingkat yang signifikan memerlukan beberapa intervensi.

\section{Penutup}

Sasaran Keselamatan Pasien. rumah sakit diwajibkan untuk meningkatkan mutu pelayanan kesehatan yang salah satunya adalah melalui sasaran keselamatan pasien. Sasaran keselamatan pasien yang dimaksud dalam akreditasi rumah sakit adalah Sasaran Keselamatan Pasien (SSP) yang terdiri dari Sasaran I adalah Ketepatan Identifikasi Pasien, Sasaran II adalah Peningkatan komunikasi yang efektif, Sasaran III adalah Peningkatan keamanan obat yang perlu diwaspadai, Sasaran IV adalah Kepastian tepat lokasi, tepat prosedur, dan tepat pasien operasi, Sasaran IV adalah Pengurangan risiko infeksi terkait pelayanan kesehatan, VI adalah Pengurangan risiko pasien jatuh. Bentuk-bentuk kesalahan yang terjadi di rumah sakit seperti kesalahan dalam pelayanan atau pengobatan yang dikarenakan kesalahan dalam mengidentifikasi pasien dengan benar, kesalahan dalam pemberian obat dikarenakan Look-Alike Sound-Alike, kesalahan pelayanan karena komunikasi yang tidak efektif baik dari perawat-perawat atau perawat-pelayanan kesehatan lain, dan terjadinya pasien jatuh yang mengakibatkan cedera pasien rawat inap.

\section{Daftar Pustaka}


Afriza N.Reno, Lestari Yuniar, Yetti Husna . (2018). Analisis Pelaksanaan Sasaran Keselamatan Pasien Di Rawat Inap Rumah Sakit Umum Daerah Padang Pariaman . Jurnal fk unand. 7(4):48-55

Anggraini Sri, Chanif. (2020). Efektifitas Pemberian Posisi Kepala Elevasi Pada Pasien Hipertensi Emergensi. Ners Muda. 1(2):78-87

Arrum Diah, Salbiah, Manik Murniati. (2015). Pengetahuan Tenaga Kesehatan Dalam Sasaran Keselamatan Pasien Di Rumah Sakit Sumatera Utara. Idea Nursing Journal. 6(2) : 1-6

Dwi S.Mardika, Zuhrotunida,Syahridal. (2016). Implementasi Sasaran Keselamatan Pasien Di Ruang Rawat Inap RSU Kabupaten Tangerang. JKFT. No 2 . 59-69

Firawati. Pabuty, A. Putra, A.S. (2012). Pelaksanaan Program Keselamatan Pasien di RSUD Solok. Jurnal Kesehatan Masyrakat. 6(2). 73-79.

Hani J.Nanda ,Ahid M.Ahmad. (2018). Penerapan Standar Keselamatan Pasien di Rumah Sakit Umum Daerah Provinsi Nusa Tenggara Barat. Jurnal Kesehatan Poltekkes Ternate. 11(2): 93 - 108

Herawati, Y., T. (2015). Budaya Keselamatan Pasien di Ruang Rawat Inap Rumah Sakit X Kabupaten Jember. Jurnal Ikatan Kesehatan Masyarakat. 11(1), 54-58.

Kamil Hajjul . Patient Safety . Idea Nursing Journal .1(1) : 1-8

Rahmayunia K.Imelda, Stenalia Yelpio. (2019). Deskripsi Penerapan patient Safety pada pasien di bangsal bedah. Jurnal Human Care .4(2): 86-94

Riskiyah.(2018).Pengetahuan Perawat Ruang Rawat Inap Tentang Penerapan Sasaran Keselamatan Pasien. Journal of Islamic Medicine. 2(4):14-25

Simamora, R. H. (2018). Buku ajar keselamatan pasien melalui timbang terima pasien berbasis komunikasi efektif: SBAR. Medan: USUpress.

Simamora, R. H. (2020). Learning of Patient Identification in Patient Safety Programs Through Clinical Preceptor Models. Medico Legal Update, 20(3), 553-556. 